\title{
Social and physical environmental correlates of independent mobility in children: a systematic review taking sex/gender differences into account
}

\author{
Isabel Marzi ${ }^{1 *}$, Yolanda Demetriou ${ }^{2}$ and Anne Kerstin Reimers ${ }^{1}$
}

\begin{abstract}
Background: Children's independent mobility (CIM) is an important contributor to physical activity and health in children. However, in the last 20 years CIM has significantly decreased. To develop effective intervention programs to promote CIM, the impact of the environment on CIM must be identified. This review seeks to provide an overview of sex/gender-specific socio-ecological correlates of CIM.

Methods: A systematic literature search of five databases (PubMed, Psyclnfo, Scopus, Medline, Web of Science) was conducted with a priori defined eligibility criteria and identified 1838 potential articles published between January 1990 and November 2017. Two independent reviewers screened the literature and identified and rated methodological quality of the studies. Related factors of CIM were summarized separately for CIM license (parental permission to travel independently) and CIM destination (destinations to which a child travels independently), and separately for boys and girls using a semi-quantitative method.

Results: Twenty-seven peer-reviewed journal articles were identified which examined the relationship between the social and physical environment and CIM. Only seven studies reported results divided by sex/gender. Most associations between the environment and CIM were found in the expected direction (positive or negative) or not associated at all. The social environment seemed to be more influential for ensuring CIM than the physical environment. Neighborhood safety, fear of crime and stranger, parental support, and perception of traffic were important social environmental factors influencing CIM, while car ownership, distance, and neighborhood design were relevant physical environmental attributes. Few studies examined sex/gender-related environmental correlates of independent mobility, and those findings were inconsistent.

Conclusion: The findings of this systematic review serve as suggestions for intervention programs to increase CIM and to identify future directions in research. To establish a robust comprehension of the impact of the social and physical environment on CIM, further sex/gender-sensitive studies using comparable measurements for CIM and environmental correlates are needed.
\end{abstract}

Keywords: Independent mobility, Social environment, Physical environment, Children, Sex/gender differences

\footnotetext{
*Correspondence: isabel.marzi@hsw.tu-chemnitz.de

${ }^{1}$ Faculty of Behavioral and Social Sciences, Chemnitz University

of Technology, Chemnitz, Germany

Full list of author information is available at the end of the article
} 


\section{Background}

Physical activity is associated with numerous health benefits $[1,2]$. However, in 2010 more than $80 \%$ of schoolaged children worldwide did not to meet the World Health Organization recommendation of $60 \mathrm{~min}$ of moderate to vigorous-intensity physical activity daily [3, 4]. Walking or cycling for transport, otherwise known as 'active travel', is one way in which children can increase their levels of physical activity. A number of studies have examined the contribution of active travel to overall activity levels and health [5] and have generally found that children who walk to school are more likely to engage in physical activity overall and are more likely to meet physical activity guidelines than children who travel motorized. Additionally, children who walk or cycle to school have a lower BMI than those who are passive travelers [6].

Children's independent mobility (CIM) defined as "the freedom of children to travel around their neighborhood or city without adult supervision" [7] is one important contributor to active travel and underscores the relationship between active travel behavior and physical activity. For both boys and girls, CIM is positively associated with physical activity on weekdays and, furthermore, for girls on weekends [8].

In addition to these health outcomes, CIM is associated with cognitive and motor development as well as social competencies of children [9-12]. Rissotto and Tonucci [13] showed that CIM has positive effects on cognitive development of children due to social and environmental experience. Furthermore, children who are independently mobile have more social competencies as they spend more time with peers than others [12]. In contrast, a lower CIM level predicts greater feelings of loneliness [14].

However, CIM has significantly decreased over the past 20 years $[15,16]$. In Australia, the proportion of children travelling to school independently was $61 \%$ in 1991 but this proportion declined to 32\% by 2012 [15]. Increased car use corresponding to a decline in independent mobility was recorded in several countries [17]. In Denmark, car use doubled between 1978 and 2000; within the same period the number of children walking to school fell by almost 40\% [17]. Although Finnish children still enjoy the highest amount of independent mobility [18], CIM significantly decreased over a period of 20 years in Finland as well [16]: In the inner city of Helsinki, the proportion of children travelling independently to and from school decreased from 82 to $50 \%$.

Socio-ecological models postulate multiple environmental influences on health behavior [19]. Children in particular are less autonomous concerning their physical activity and mobility and are more likely to be influenced by their environment than are adults [20]. Thus, understanding social and physical environmental correlates of independent mobility among children is an important prerequisite to develop effective interventions to increase the number of children engaging in independent mobility. Empirical studies examined various physical environmental (e.g., walkability, and urbanity) and social environmental (e.g., parental fear, perception of danger, and social support) factors that influence CIM. Changes in children's physical environments over the past 20 years, such as more car traffic and fewer playgrounds, affect active travel behaviors and deter CIM [17, 21, 22]. Access to organized leisure activities determines the extent of CIM as Fyhri, Hjorthol [17] reported that children are often taken to leisure activities by car, because activities take place outside the immediate neighborhood. Additionally, due to an increasing crime rate, high urbanization, and long distances to school, parents limit CIM by prohibition [17, 23]. Moreover, the neighborhood environment and the local social network determine CIM [24]. Mothers' perception of social danger and traffic around school has also been found to inhibit independent active travel $[25,26]$. In contrast, older siblings or dog ownership are associated with greater CIM as older siblings and dogs provide parents an increased sense of safety [27].

Accounting for sex/gender differences with regard to independent mobility is important. Gender theories postulate that such differences are due to socially determined gender roles; gender-typed patterns of behavior occur based on socialization processes [28, 29]. Generally, girls tend to be less physically active than boys and less inclined to participate in organized sports [3, 30, 31]. Regarding CIM, sex/gender differences appear to exist, with girls having less freedom to travel around without parental supervision than boys [24, 32, 33]. Furthermore, boys seem to become independently mobile earlier than girls: Brown et al. [34] showed that $60 \%$ of boys between 4 and 6 years living in England are allowed to go out alone whereas the proportion of girls stands around $44 \%$. As CIM is related to physical activity, knowing the reasons for low levels of CIM and considering them in intervention programs could be one way to increase physical activity in girls. There is evidence for different mechanisms explaining sex/gender differences in CIM: The higher protectiveness of parents about their daughters than about their sons and higher safety concerns can limit girls' independent mobility level [25, 34-36].

Health promotion programs are increasingly designed based on the socio-ecological perspective, thus identifying various levels of contextual influences on children's independent mobility is required [37, 38]. Nevertheless, to the best of our knowledge no comprehensive overview 
of socio-ecological correlates of independent mobility in children has yet been published. For active-but not independent-travel a review published by Panter et al. [39] pointed out the importance of environmental determinants of active travel behaviors. However, for CIM no such summary is available as a recent meta-analytical review by Sharmin and Kamruzzaman [40] focused solely on the association between the built environment and CIM. A systematic review by Qui and Zhu [41] focused on housing and community environments and its impact on CIM. Nevertheless, this review has its limitations, because no distinction was made between different types of CIM, i.e., range, destination, time or license and no quality assessment was conducted to identify current research gaps. Additionally, sex/gender-related differences concerning the correlates of CIM have not been incorporated in previous reviews [40, 41]. Thus, this systematic review aims to provide an overview of socioecological correlates of CIM with a particular focus on differences between boys and girls and categorized by different CIM types.

\section{Methods}

This systematic review was conducted and is reported based on the Preferred Reporting Items for Systematic Reviews and Meta-Analyses (PRISMA) guidelines [42].

\section{Search strategy}

The literature search was conducted on 7 November 2017 using the databases PubMed, Medline, Scopus, PsycInfo and Web of Science Core Collection. The search strategy included a combination of terms for independent mobility ("independent mobil*"), correlates (environment" OR neighborhood OR family OR families OR home OR parent* OR mother* OR father* OR sibling* OR urban* OR park*) and children (kids* OR child* OR girl* OR boy*). Additional articles were sought by reviewing reference lists of included full text articles and citations of full text articles using the Web of Science "Citation Network" statistics of each study.

\section{Eligibility criteria}

Studies were deemed eligible if they met all following inclusion criteria: (1) subjects of the study were healthy children (age 3-12 years or the average age was in this range); (2) at least one association between CIM and an environmental (social and physical) correlate was examined; (3) an appropriate study design was used (crosssectional or longitudinal; no case or intervention study); (4) the study employed a quantitative design; (5) the study was published in a peer-reviewed journal, written in English or German language; (6) the study was published after 1990, because in that year Hillman et al. [22] introduced the term "children's independent mobility", in their seminal study on this topic. An exception was made for some intervention studies if a cross-sectional analysis of the association of interest was reported.

If the study examined attitudes towards independent mobility instead of CIM itself, it was excluded. Studies referring to active commuting to school or active travel were only included if they clearly defined whether children travelled independently.

\section{Environmental correlates}

Social and physical correlates were selected based on the socio-ecological model of Sallis et al. [19]. Correlates of the social environment were categorized into three subcategories: children's perceived neighborhood environment (e.g., fear of stranger), parents' perceived neighborhood environment (e.g., neighborhood friendliness), and social cultural environment (e.g., parental rules towards CIM). To categorize correlates of the physical environment the following five domains were established based on Sallis et al. [19] and Ding et al. [43]: home environment (e.g., car ownership), school environment (e.g., school-specific walkability), recreational environment (e.g., access to parks and playground), neighborhood design (e.g., degree of urbanization), and transport environment (e.g., traffic). Studies with only socio-demographic characteristics of the child, the family and/or household were excluded.

\section{Study selection}

The study selection occurred in three steps compromising (1) title-screening, (2) abstract-screening, and (3) full-text-screening by two independent researchers (IM, CS). Studies were included or excluded depending on the eligibility criteria. During each step of the screening process, all references that could not be conclusively excluded were kept for further screening in the next step. Disagreement between the two reviewers on final inclusion was resolved by discussion with a third researcher (AKR). The selection process was documented using the reference management software EndNote X7 [44].

\section{Data extraction}

The following data was extracted from each article: author(s); year of publication; country; study design; sample description (number of participants, age, sex/gender); definition, measurement, and instrument of CIM; type, measurement, and instruments of examined correlates; and main study results on the relationship between social and physical environmental factors and CIM (see Additional file 1). CIM was classified as CIM range, CIM time, CIM destination, or CIM license [40]. CIM range describes the distance children can travel independently 
from their home. CIM time defines how many minutes children can travel outside of their home independently. Destinations a child independently travels to are included in the term CIM destination. Whether parents allow children to travel independently is defined as CIM license.

\section{Quality assessment}

The methodological quality of the studies included was evaluated by two independent reviewers (IM, KB) using 11 a priori defined quality criteria based on existing quality assessments published by Downes et al. [45] and Uijtdewilligen et al. [46]. Each criterion was either coded as "no" or "unclear" (0) if the study either did not meet the criterion or the criterion was not mentioned. If the study provided information on the quality item but only in parts, the criterion was coded as "partial" (0.5), while if the study completely met the criterion it was coded as "yes" (1). If a study referred to another publication containing relevant information for scoring the quality items, the study of interest was consulted. However, if the additional source did not provide the requested information or just in parts, the criterion was coded-according to the defined coding system-with "no" or "unclear", respectively. As many studies included multiple correlates (e.g., social factors, and physical factors), criterion eight was scored on a scale ranging from 0 to 1 . For example, if a study analyzed four different types of correlates of which three were measured with a reliable tool, a score of 0.75 was calculated. The methodological quality score of each study was calculated by the percentage of fulfilled criteria relative to the sum of all criteria (11 points in total). A quality score of $\geq 70 \%$ was considered high methodological quality, while a score of $<70 \%$ was considered insufficient methodological quality [46]. The quality assessment for each study is presented in Additional file 2.

\section{Synthesis of results}

Due to the heterogeneity of social and physical environmental correlates and outcome measures of CIM a meta-analysis of the selected studies was considered inappropriate. The results of all selected studies were analyzed using a semi-quantitative method. In addition to associations between the social and physical environment and independent mobility in children in general, associations were considered separately for both, girls and boys, with appropriate studies. Bivariate associations between CIM and environmental correlates (19 studies) and multivariate regression models (20 studies) were considered separately as various socio-demographic, social, and physical environmental correlates were integrated into multiple regression models. As no study evaluated CIM time and only three CIM range, the results were only analyzed separately for CIM destination and CIM license.

The strength of evidence was adapted from previously published scoring systems [11, 43, 47]. If $0-33 \%$ of studies showed a significant association $(\mathrm{p} \leq 0.05)$ of CIM and social or physical environmental correlates, the findings were classified as no association (0). If $34-59 \%$ of studies demonstrated significant associations, the findings were classed as being inconsistent (?). If $60-100 \%$ reported significant associations between CIM and the social or physical environment, the findings were categorized as positive $(+)$ or negative $(-)$, depending on the direction of the relationship. For less than four available studies for positive or negative associations the evidence was rated as limited (small,+- ). Additionally, the methodological quality of the studies was included in scoring the strength of evidence. If $60-100 \%$ of high quality studies showed a significant correlation, the findings were considered strong evidence for a positive $(++)$ or negative (-) correlation.

As the publications of Foster et al. [36], Villanueva et al. [48] and Villanueva et al. [33] analyzed the same study population, some social and physical environmental correlates were doubled in the results. For that reason significant associations of doubled correlates of these publications were considered as one study result for scoring the strength of evidence.

\section{Results}

\section{Flow chart}

A total of 1838 potentially relevant articles (2165 including duplicates) were identified by the database search and screened based on title and abstract. Next, the full texts of 59 studies were retrieved for detailed review. As 34 studies were excluded due to inappropriate age range, aim of study, study design or for multiple reasons, 25 studies identified by the database screenings have been included in this systematic review. Two additional relevant publication were identified by backward reference tracking, yielding a total of 27 papers included in this systematic review (Fig. 1).

\section{Characteristics of included studies}

General study characteristics are summarized in Table 1. An additional file shows more details of the studies included (see Additional file 1). More than $80 \%$ of the selected studies were cross-sectional, two were longitudinal and another two studies were longitudinal including cross-section analyses. The sample sizes ranged from 181 children [49] to a study population of 2110 children [50]. Nearly half of the studies were conducted in Europe, with 10 from either Australia or New Zealand, five from North America or Canada and one from Asia. Most studies 


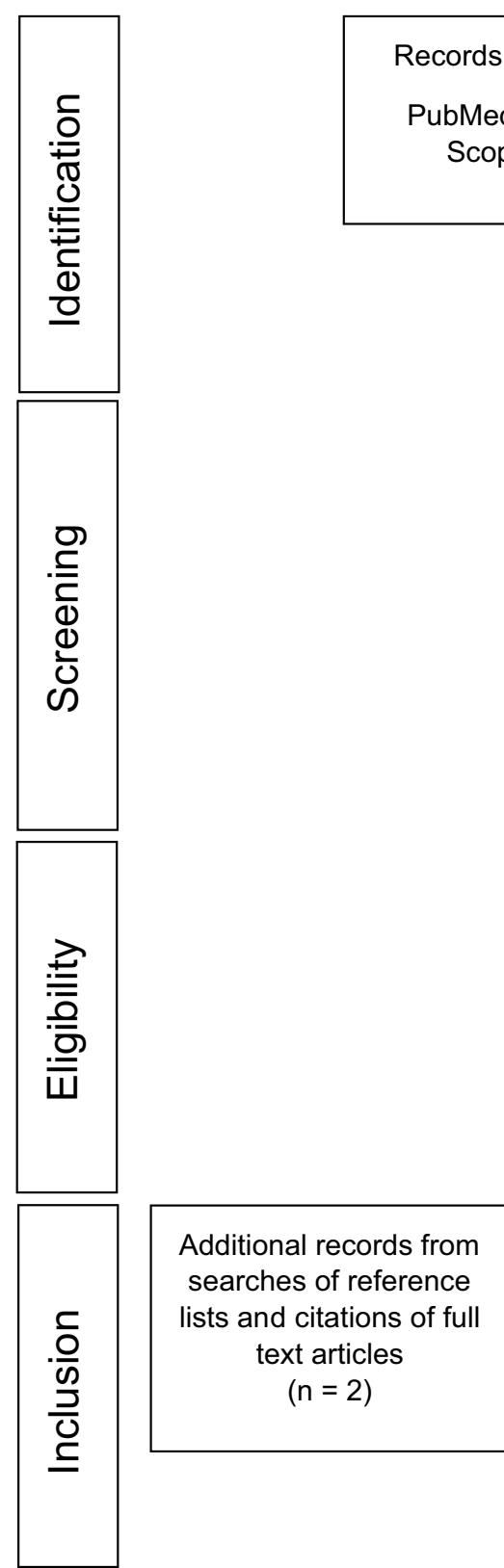

Records identified through database searching
PubMed $=411$, Medline $=72$, Psyclnfo $=45$,
Scopus $=1443$, Web of Science $=194$ $(n=2165)$

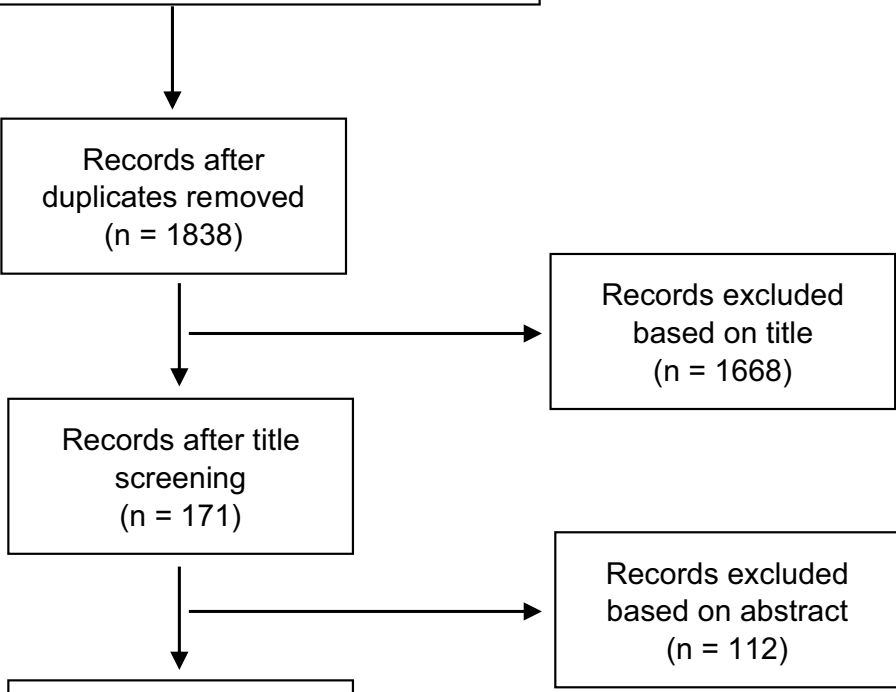

\section{Full-text articles} assessed for eligibility $(n=59)$

Fig. 1 Flow chart

(85\%) were published between 2010 and 2017 with the earliest publication in 2001 [12].

In the majority of studies, the mean age of the sample population ranged from 9 to 12 years [12, 23-25, 27, 32 , 33, 35, 36, 48, 49, 51-61]. Fewer studies focused on younger children aged 6 to 9 years [26, 50, 59, 62-64]. All studies targeted girls and boys, but merely seven studies separated results by sex/gender [33, 35, 36, 48, 52-54]. Of all studies, eighteen described CIM by destinations a child traveled independently to. Fewer studies examined
CIM licenses. CIM range was evaluated by another three studies. No study evaluated CIM as independent time outside. Ten studies utilized solely parent-report measures of CIM, and a further six studies applied children's self-reporting. Another ten studies combined child and parental report measurements of CIM. Twenty-one studies $[12,23-25,32,33,35,36,48,49,52-57,60-64]$ examined both social and physical environmental correlates of CIM. Three studies $[50,51,58]$ focused on the relationship between the physical environment and CIM and 
Table 1 Characteristics of studies included ( $n=27$ studies)

\begin{tabular}{|c|c|c|}
\hline Characteristics & N (\%) & Study source \\
\hline \multicolumn{3}{|l|}{ Study design } \\
\hline Cross-sectional & $23(85)$ & {$[12,23-26,32,33,35,36,48,50,51,53-59,61-64]$} \\
\hline Longitudinal including cross-sectional analyses & $2(8)$ & {$[27,49]$} \\
\hline Longitudinal & $2(8)$ & {$[52,60]$} \\
\hline \multicolumn{3}{|l|}{ Sample size } \\
\hline$<500$ & $14(52)$ & {$[12,25,27,49,53,55-61,63,64]$} \\
\hline$>500$ & $13(48)$ & {$[23,24,26,32,33,35,36,48,50-52,54,62]$} \\
\hline \multicolumn{3}{|l|}{ Geographic origin } \\
\hline Europe & $11(41)$ & {$[12,23,25,35,51,52,56,58,59,62,64]$} \\
\hline North America/Canada & $5(18)$ & {$[24,26,32,61,63]$} \\
\hline Australia/New Zealand & $10(37)$ & {$[27,33,36,48,49,53-55,57,60]$} \\
\hline Asia & $1(4)$ & {$[50]$} \\
\hline \multicolumn{3}{|l|}{ Publication year } \\
\hline 2010-2017 & $23(85)$ & {$[23-27,32,33,35,36,48-55,57-61,63]$} \\
\hline 1990-2009 & $4(15)$ & {$[12,56,62,64]$} \\
\hline \multicolumn{3}{|l|}{ IM definition ${ }^{\mathrm{a}}$} \\
\hline CIM range & $3(11)$ & {$[35,56,63]$} \\
\hline CIM time & 0 & \\
\hline CIM destination & $18(67)$ & {$[23,25,26,32,33,36,48,51-55,57-60,62,64]$} \\
\hline CIM license & $10(37)$ & {$[12,23,24,27,49,53,56,58,61,64]$} \\
\hline No response & $1(4)$ & {$[50]$} \\
\hline \multicolumn{3}{|l|}{ IM Measurement } \\
\hline Child reported & $6(22)$ & {$[51,52,55,59,60,62]$} \\
\hline Parent reported & $10(37)$ & {$[12,24-27,35,49,56,61,63]$} \\
\hline Child and parent reported & $10(37)$ & {$[23,32,33,36,48,53,54,57,58,64]$} \\
\hline No response & $1(4)$ & [50] \\
\hline \multicolumn{3}{|l|}{ Correlates measurement } \\
\hline Objective & $1(4)$ & [51] \\
\hline Subjective & $10(37)$ & {$[12,24-27,35,56,59,62,63]$} \\
\hline Objective and subjective & $16(59)$ & {$[23,32,33,36,48-50,52-55,57,58,60,61,64]$} \\
\hline
\end{tabular}

${ }^{\text {a }}$ More than $100 \%$ possible due to multiple types of CIM in one study

two further studies $[26,59]$ reported only the association between social environmental factors and CIM. For social and physical environmental factors most studies combined objective and subjective measurements. Ten studies applied only subjective measurements and one study used solely objective measurements.

\section{Results of methodological quality assessment}

The study quality was rated high in 12 studies $[25,27,32$, $36,49,51,52,55,59-61,64]$ and low in 15 studies [12, 23, $24,26,33,35,48,50,53,54,56-58,62,63]$. The agreement between the two reviewers in the methodological quality of included studies (IM and KB) was 75\% (Cohen's kappa $\kappa=0.752$ ). In discussion of individual study quality scores, a final agreement of $100 \%$ was achieved. The methodological quality criteria and the number and proportion of studies fulfilling the criteria are presented in
Table 2; more detailed quality assessments of each study included is presented in an additional file (see Additional file 2). All 27 studies contained clearly defined aims. As the aim of the majority of the studies was to identify causal relationships between the social and physical environment and CIM, most studies did not fulfil the criterion regarding study design. Twenty-five studies failed to meet criteria for response rate, since the response rate was less than $80 \%$ or not clearly defined. Only three studies undertook measures to address and categorize nonresponders. Standardized methods of acceptable quality were used to measure CIM and correlates in more than $50 \%$ of the studies. One study lacked clearly defined statistical methods and internally consistent results. More than $80 \%$ of the studies presented results for all the analyses described in the methods; four studies were missing some data. 
Table 2 Criteria for methodological quality assessment and number (\%) of studies scoring points for each criterion

\begin{tabular}{|c|c|c|c|}
\hline & & \multicolumn{2}{|c|}{$\begin{array}{l}\text { Studies fulfilling } \\
\text { the criteria } \mathrm{n}(\%)\end{array}$} \\
\hline & & Yes & Partial \\
\hline \multicolumn{4}{|c|}{ Criteria } \\
\hline 1 & Were the aims/objectives of the study clear? & $27(100)$ & $0(0)$ \\
\hline \multicolumn{4}{|c|}{ Methods } \\
\hline 2 & Was the study design appropriate for the stated aims? & $6(22)$ & $21(78)$ \\
\hline 3 & $\begin{array}{l}\text { Were the main features of the study population stated (description of sampling frame, distribution by } \\
\text { age and sex/gender)? }\end{array}$ & $14(52)$ & $13(48)$ \\
\hline 4 & Was the response rate at least $80 \% ?$ & $2(8)$ & $0(0)$ \\
\hline 5 & Were measures undertaken to address and categorize non-responders? & $3(11)$ & $0(0)$ \\
\hline 6 & Were the exposure and outcome variables measured appropriate to the aims of the study? & $17(63)$ & $10(37)$ \\
\hline 7 & Were standardized methods of acceptable quality used to measure IM?a & $12(44)$ & $6(22)$ \\
\hline 8 & Were standardized methods of acceptable quality used to measure correlates? ${ }^{a}$ & $18(69)$ & $6(22)$ \\
\hline 9 & $\begin{array}{l}\text { It is clear what was used to determine statistical significance and/or precision estimated (e.g., p } \\
\text { values, confidence intervals)? }\end{array}$ & $23(85)$ & $2(8)$ \\
\hline \multicolumn{4}{|c|}{ Results } \\
\hline 10 & Were the results internally consistent? & $26(96)$ & $1(4)$ \\
\hline 11 & Were the results presented for all the analyses described in the methods? & $23(85)$ & $4(15)$ \\
\hline
\end{tabular}

a Reliability: ICC > 0.70; Cronbach's alpha > 0.65, pilot testing, published previously

\section{Social environment and CIM destination}

A total of 48 associations of social environmental correlates and independent mobility to different destinations were reviewed in 10 studies. Some studies investigated similar constructs but employed different terminologies. Thus, these variables (e.g., safe for children, and safe place) were collected and an umbrella term was used (e.g., neighborhood safety) yielding a total sum of 23 social environmental correlates (Table 3). Three of four correlates describing children's perceived neighborhood environment were significantly associated with CIM destination in the expected direction: fear of strangers $(67 \%)$, neighborhood safety $(100 \%)$, and many other children residing within their area (100\%). Concerning the parental perceived neighborhood environment, 75\% of all comparisons showed significant associations with CIM destination, including fear of strangers (100\%), fear of crime (100\%), neighborhood friendliness (100\%), perception of traffic (63\%), informal social control (100\%), and people out on walks in the neighborhood (100\%). Less evidence existed for associations between the social cultural environment and CIM destination; four of eight variables had more than $60 \%$ of significant associations. Mobility licenses (100\%), confidence in children's abilities $(100 \%)$, a child's personal safety $(100 \%)$, and having friends (100\%) were positively associated with CIM destination. Several relationships of social environmental correlates and CIM destination were categorized as inconsistent, including neighborhood friendliness (children; 50\%), neighborhood safety (parents; 40\%), parental rules (50\%), and parent encouragement (50\%). No association showed strong evidence with $60-100 \%$ of high quality studies reporting the association in the expected direction.

\section{Physical environment and CIM destination}

The evidence for associations between the physical environment and CIM destination was much weaker than for social environmental correlates. Only 11 of 23 variables demonstrated evidence for significant associations with CIM destination, reviewed in 14 studies (Table 3). Car ownership (60\%), dog ownership (100\%), distance to school (100\%), school density (100\%), remote places (100\%), population density $(100 \%)$, degree of urbanization (71\%), urban structure (100\%) were consistently associated with CIM destination in the expected direction, but with little evidence. Furthermore, different neighborhood designs, such as mainly single-family housing, densely built up residential areas and big buildings were associated with CIM. Inconsistent associations were reported for five physical environmental variables, including bike ownership (50\%), school-specific walkability (40\%), access to parks (33\%), street connectivity (38\%), and land use mix (50\%). Transport attributes, including walking facilities, biking facilities, streetlight density and traffic (objective), were also not consistently associated with CIM destination. 
Table 3 Social and physical environmental correlates of CIM Destination

\begin{tabular}{|c|c|c|c|c|c|c|}
\hline \multirow[t]{2}{*}{ Correlates } & \multirow[t]{2}{*}{ Study source } & \multicolumn{3}{|l|}{ Association with CIM } & \multicolumn{2}{|c|}{ Strength of evidence } \\
\hline & & + & 0 & - & Association $^{a}$ & $\mathrm{n} / \mathrm{N}(\%)^{\mathbf{b}}$ \\
\hline \multicolumn{7}{|l|}{ Social environment } \\
\hline \multicolumn{7}{|c|}{ Perceived neighborhood environment (children) } \\
\hline Fear of strangers & {$[32,33]$} & & [33] F & [33] M; [32] & - & $2 / 3(67)$ \\
\hline $\begin{array}{l}\text { Neighborhood friendli- } \\
\text { ness }\end{array}$ & [33] & [33] M & [33] F & & $?$ & $1 / 2(50)$ \\
\hline Neighborhood safety & {$[32,33] ;[62]^{c}$} & [33] M, F; [32] & & {$[62]^{c}$} & + & $4 / 4(100)$ \\
\hline $\begin{array}{l}\text { Many other children } \\
\text { within their area }\end{array}$ & {$[33,36]$} & $\{[33] \mathrm{M}, \mathrm{F} ;[36] \mathrm{M}, \mathrm{F}\}^{\mathrm{e}}$ & & & + & $2 / 2(100)$ \\
\hline \multicolumn{7}{|c|}{ Perceived neighborhood environment (parents) } \\
\hline Sense of community & {$[52]$} & & {$[52](M, F)$} & & 0 & $0 / 2(0)$ \\
\hline Fear of strangers & {$[32,36]$} & & & [32]; [36] M, F & - & $3 / 3(100)$ \\
\hline Fear of crime & {$[63]$} & & & {$[63]$} & - & $1 / 1(100)$ \\
\hline $\begin{array}{l}\text { Neighborhood friendli- } \\
\text { ness }\end{array}$ & {$[33,36,60]$} & $\begin{array}{l}\{[33] \mathrm{M}, \mathrm{F} ;[36] \mathrm{M}, \mathrm{F}\} \text {; } \\
\quad[60]\end{array}$ & & & + & $3 / 3(100)$ \\
\hline Neighborhood safety & {$[52,63] ;[52]^{c}$} & {$[52] \mathrm{F} ;[63]$} & {$[52] \mathrm{M} ;[52]^{\mathrm{c}} \mathrm{M}, \mathrm{F}$} & & $?$ & $2 / 5(40)$ \\
\hline Perception of traffic & $\begin{array}{l}{[36,52,62,63] ;[32,} \\
33]^{d(2)} ;[33,60,63]^{c}\end{array}$ & {$[33]^{c} M, F ;[63]^{c}$} & 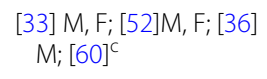 & $\begin{array}{l}{[62,63] ;[32]^{d(2)} ;} \\
\quad[36] \mathrm{F} ;[33] \mathrm{M}, \mathrm{F}\end{array}$ & - & 10/16 (63) \\
\hline $\begin{array}{l}\text { Often people out on } \\
\text { walks in the neighbor- } \\
\text { hood }\end{array}$ & {$[33]$} & [33] M, F & & & + & $2 / 2(100)$ \\
\hline Informal social control & {$[36]$} & [36] M, F & & & + & $2 / 2(100)$ \\
\hline \multicolumn{7}{|c|}{ Social cultural environment } \\
\hline Mobility license & {$[53-55,64]$} & $\begin{array}{l}\text { [53] M, F; [54] M, F; } \\
{[55,64]}\end{array}$ & & & + & $6 / 6(100)$ \\
\hline $\begin{array}{l}\text { Parental rules (towards } \\
\text { IM) walking }\end{array}$ & {$[52]$} & & {$[52] \mathrm{M}, \mathrm{F}$} & & 0 & $0 / 2(0)$ \\
\hline $\begin{array}{l}\text { Parental rules (towards } \\
\text { IM) play outside }\end{array}$ & {$[52]$} & [52] M & [52] F & & $?$ & $1 / 2(50)$ \\
\hline $\begin{array}{l}\text { Parent encourage for } \\
\text { walking/cycling }\end{array}$ & {$[52]$} & & {$[52] \mathrm{M}$} & {$[52] \mathrm{F}$} & $?$ & $1 / 2(50)$ \\
\hline $\begin{array}{l}\text { Friend encourage for } \\
\text { walking/cycling }\end{array}$ & {$[52]$} & & [52] M, F & & 0 & $0 / 2(0)$ \\
\hline $\begin{array}{l}\text { Confidence in children's } \\
\text { abilities }\end{array}$ & {$[33,60]$} & [33] M, F; [60] & & & + & $3 / 3(100)$ \\
\hline Child's personal safety & {$[33,60]$} & [33] M, F; [60] & & & + & $3 / 3(100)$ \\
\hline $\begin{array}{l}\text { Fearful of child engag- } \\
\text { ing in antisocial } \\
\text { behavior }\end{array}$ & {$[33]$} & & [33] M, F & & 0 & $0 / 2(0)$ \\
\hline Parental physical activity & {$[63]$} & & {$[63]$} & & 0 & $0 / 1(0)$ \\
\hline Parent activity with child & {$[63]$} & & {$[63]$} & & 0 & $0 / 1(0)$ \\
\hline $\begin{array}{l}\text { Many children we know } \\
\text { walk or cycle to school }\end{array}$ & {$[60]$} & & {$[60]$} & & 0 & $0 / 1(0)$ \\
\hline Having friends & {$[33]$} & [33] M, F & & & + & $2 / 2(100)$ \\
\hline \multicolumn{7}{|l|}{ Physical environment } \\
\hline \multicolumn{7}{|l|}{ Home environment } \\
\hline Car ownership & {$[32,50,52,62]$} & & [32]; [52] F & {$[50,62] ;[52] \mathrm{M}$} & - & $3 / 5(60)$ \\
\hline Dog ownership & {$[27]$} & {$[27]$} & & & + & $1 / 1(100)$ \\
\hline Bike ownership & {$[33]$} & [33] F & [33] M & & $?$ & $1 / 2(50)$ \\
\hline Size of backyard & {$[33]$} & & [33] M, F & & 0 & $0 / 2(0)$ \\
\hline \multicolumn{7}{|l|}{ School environment } \\
\hline Distance & {$[32,50,51,62]$} & & & {$[32,50,51,62]$} & - & $4 / 4(100)$ \\
\hline
\end{tabular}


Table 3 (continued)

\begin{tabular}{|c|c|c|c|c|c|c|}
\hline \multirow[t]{2}{*}{ Correlates } & \multirow[t]{2}{*}{ Study source } & \multicolumn{3}{|c|}{ Association with CIM } & \multicolumn{2}{|c|}{ Strength of evidence } \\
\hline & & + & 0 & - & Association ${ }^{a}$ & $n / N(\%)^{b}$ \\
\hline $\begin{array}{l}\text { School-specific walk- } \\
\text { ability }\end{array}$ & {$[33,36,52,62]$} & $\{[33] \mathrm{F} ;[36] \mathrm{F}\}^{\mathrm{e}} ;[62]$ & $\begin{array}{l}\{[33] \mathrm{M} ;[36] \mathrm{M}\} \text {; [52] } \\
\quad \mathrm{M}, \mathrm{F}\end{array}$ & & $?$ & $2 / 5(40)$ \\
\hline School characteristics & {$[52]$} & & {$[52] \mathrm{M}, \mathrm{F}$} & & 0 & $0 / 2(0)$ \\
\hline School density & {$[50]$} & {$[50]$} & & & + & $1 / 1(100)$ \\
\hline \multicolumn{7}{|l|}{ Recreational environment } \\
\hline Parks & {$[33,60]$} & [33] M & [33] F; [60] & & $?$ & $1 / 3(33)$ \\
\hline $\begin{array}{l}\text { Quality and quantity of } \\
\text { public open spaces }\end{array}$ & {$[55]$} & & {$[55]$} & & 0 & $0 / 1(0)$ \\
\hline Remote places & [51] & [51] & & & + & $1 / 1(100)$ \\
\hline \multicolumn{7}{|l|}{ Neighborhood design } \\
\hline Street connectivity & {$[32,50] ;[52]^{d(3)}$} & & $\begin{array}{l}{[52] \mathrm{M}, \mathrm{F} ;[52](\mathrm{M}) ;[52]} \\
\quad \mathrm{M}, \mathrm{F}\end{array}$ & {$[32,50] ;[52] \mathrm{F}$} & $?$ & $3 / 8(38)$ \\
\hline $\begin{array}{l}\text { Neighborhood walk- } \\
\text { ability }\end{array}$ & {$[52]$} & & {$[52] \mathrm{M}, \mathrm{F}$} & & 0 & $0 / 2(0)$ \\
\hline Land use mix & {$[32,50,52]$} & & [52] M; [50] & [32]; [52] F & $?$ & $2 / 4(50)$ \\
\hline Population density & {$[50]$} & & & {$[50]$} & - & $1 / 1(100)$ \\
\hline $\begin{array}{l}\text { Degree of urbanization } \\
\text { (ref: urban) }\end{array}$ & $\begin{array}{l}{[23,50,53,54,58,} \\
\quad 62,64]\end{array}$ & [54] & {$[53]$} & $\begin{array}{l}{[23,50,58,62} \\
64]\end{array}$ & - & $5 / 7(71)$ \\
\hline Urban structure (new) & {$[32]$} & {$[32]$} & & & + & $1 / 1(100)$ \\
\hline Street-trees & {$[32]$} & & {$[32]$} & & 0 & $0 / 1(0)$ \\
\hline $\begin{array}{l}\text { Densely built up resi- } \\
\text { dential areas }\end{array}$ & [51] & [51] & & & + & $1 / 1(100)$ \\
\hline $\begin{array}{l}\text { Mainly single-family } \\
\text { housing }\end{array}$ & [51] & {$[51]$} & & & + & $1 / 1(100)$ \\
\hline $\begin{array}{l}\text { Big building and public } \\
\text { transport hubs }\end{array}$ & [51] & & & [51] & - & $1 / 1(100)$ \\
\hline \multicolumn{7}{|l|}{ Transport environment } \\
\hline Walking facilities & {$[52] ;[60] ;[32]^{c}$} & {$[60]$} & [52] M, F & {$[32]^{c}$} & $?$ & $2 / 4(50)$ \\
\hline Biking facilities & {$[60]$} & & {$[60]$} & & 0 & $0 / 1(0)$ \\
\hline Streetlight density & {$[52]$} & & {$[52] \mathrm{M}, \mathrm{F}$} & & 0 & $0 / 2(0)$ \\
\hline Traffic (objective) & {$[50,51] ;[32]^{d(2)}$} & & {$[32,51]$} & {$[32,50]$} & $?$ & $2 / 4(50)$ \\
\hline
\end{tabular}

Effects which are specific to different sex/gender groups are noted separately: M (male); F (female)

CIM children's independent mobility

a No evidence: no studies were identified; no association (0): 0-33\% of studies showed a significant association; inconsistent association (?): 34-59\% of studies reported significant associations; positive $(+)$ or negative $(-)$ association: $60-100 \%$ of studies demonstrated significant associations; limited evidence for a positive or negative association (small,+-$)$ ): $<4$ studies available for the associations of interest; strong evidence $(++)$ or $(--)$ association: $60-100 \%$ of high quality studies showed a significant association

${ }^{\mathrm{b}} \mathrm{n}=$ number of studies/measures reporting associations in the expected direction; $\mathrm{N}=$ number of identified studies/measures on the association of interest; (\%) = percentage of studies reporting associations in the expected direction

c Items are reversed

$d(x)$ The same study may occur twice or more often within a topic if different measures are used and show different associations; $x=$ number of measures

e $\{\ldots\}=$ study results of two studies with the same population were considered as one study

\section{Social environment and CIM license}

With regard to children's license to be independently mobile, fewer correlates were examined due to a limited number of studies (7 studies). In total eight correlates regarding the parental perceived neighborhood environment and social cultural environment were reviewed (Table 4). Perceived neighborhood attributes, such as fear of strangers (100\%), neighborhood friendliness (66\%), and neighborhood safety (100\%), were significantly associated with CIM license. Additionally, social norms (100\%) and parents' travel attitudes (100\%) showed associations with CIM license. All associations demonstrated little evidence. The associations between CIM license and parents perceived fear of crime (34\%) and traffic (34\%) were inconsistent. 
Table 4 Social and physical environmental correlates of CIM License

\begin{tabular}{|c|c|c|c|c|c|c|}
\hline \multirow[t]{2}{*}{ Correlates } & \multirow[t]{2}{*}{ Study source } & \multicolumn{3}{|c|}{ Association with CIM } & \multicolumn{2}{|c|}{ Strenght of evidence } \\
\hline & & + & 0 & - & Association $^{a}$ & $\mathrm{n} / \mathrm{N}(\%)^{\mathrm{b}}$ \\
\hline \multicolumn{7}{|l|}{ Social environment } \\
\hline \multicolumn{7}{|l|}{ Perceived neighborhood environment (parents) } \\
\hline Fear of strangers & {$[24]^{\mathrm{c}}$} & {$[24]^{c}$} & & & + & $1 / 1(100)$ \\
\hline Fear of crime & {$[61]^{c_{i}}[49]^{d(2)}$} & {$[61]^{\mathrm{c}}$} & {$[49]^{d(2)}$} & & $?$ & $1 / 3(33)$ \\
\hline Neighborhood friendliness & {$[24,61] ;[49]^{c}$} & {$[24,61]$} & {$[49]^{c}$} & & + & $2 / 3(66)$ \\
\hline Neighborhood safety & {$[24,61] ;[49]^{c}$} & {$[24,61]$} & & {$[49]^{\mathrm{c}}$} & + & $3 / 3(100)$ \\
\hline Perception of traffic & {$[24,49] ;[61]^{c}$} & {$[61]^{c}$} & {$[24,49]$} & & $?$ & $1 / 3(33)$ \\
\hline Neighborhood maintenance & {$[49]^{d(4)}$} & & {$[49]^{\mathrm{d}(4)}$} & & 0 & $0 / 4(0)$ \\
\hline \multicolumn{7}{|l|}{ Social cultural environment } \\
\hline Social norms (no support of IM) & [49] & & & [49] & - & $1 / 1(100)$ \\
\hline Parents' attitudes toward active travel modes & [24] & [24] & & & + & $1 / 1(100)$ \\
\hline Child-centered social control & [61] & & [61] & & 0 & $0 / 1(0)$ \\
\hline \multicolumn{7}{|l|}{ Physical environment } \\
\hline \multicolumn{7}{|l|}{ Home environment } \\
\hline Car ownership & [61] & & & [61] & - & $1 / 1(100)$ \\
\hline \multicolumn{7}{|l|}{ Recreational environment } \\
\hline Park availability & {$[49]^{d(2)}$} & & {$[49]^{d(2)}$} & & 0 & $0 / 2(0)$ \\
\hline Park attractiveness & [49] & [49] & & & + & $1 / 1(100)$ \\
\hline Playgrounds & {$[49]^{d(2)}$} & & {$[49]^{d(2)}$} & & 0 & $0 / 2(0)$ \\
\hline \multicolumn{7}{|l|}{ School environment } \\
\hline School density & {$[49]^{d(2)}$} & & {$[49]^{d(2)}$} & & 0 & $0 / 2(0)$ \\
\hline \multicolumn{7}{|l|}{ Neighborhood design } \\
\hline Housing unit density & {$[61]$} & & [61] & & 0 & $0 / 1(0)$ \\
\hline Degree of Urbanization & {$[23,53,58,64]$} & & [53] & {$[23,58,64]$} & - & $3 / 4(75)$ \\
\hline Neighborhood Walkability & {$[24]^{\mathrm{d}(6)}$} & & {$[24]^{\mathrm{d}(6)}$} & & 0 & $0 / 6(0)$ \\
\hline \multicolumn{7}{|l|}{ Transport environment } \\
\hline Traffic (objective) & {$[49]$} & & {$[49]$} & & 0 & $0 / 1(0)$ \\
\hline
\end{tabular}

CIM children's independent mobility

a No evidence: no studies were identified; no association (0): 0-33\% of studies showed a significant association; inconsistent association (?): $34-59 \%$ of studies reported significant associations; positive (+) or negative (-) association: $60-100 \%$ of studies demonstrated significant associations; limited evidence for a positive or negative association (small,+- ): $<4$ studies available for the associations of interest; strong evidence $(++)$ or $(--)$ association: $60-100 \%$ of high quality studies showed a significant association

b $\mathrm{n}=$ number of studies/measures reporting associations in the expected direction; $\mathrm{N}=$ number of identified studies/measures on the association of interest; (\%) = percentage of studies reporting associations in the expected direction

c Items are reversed

$d(x)$ The same study may occur twice or more often within a topic if different measures are used and show different associations; $x=$ number of measures

\section{Physical environment and CIM license}

Similar to CIM destination less significant associations existed for physical environmental attributes and CIM license; only three of nine variables demonstrated significant associations. As shown in Table 4, car ownership (100\%), park attractiveness (100\%), and degree of urbanization (75\%) were associated with CIM license in the expected direction. Strong evidence was not found for any association with physical environment. No variable of the school environment and transport environment was associated with CIM licenses and neither was availability of parks and playgrounds.

\section{Results from multivariate regression models}

The results of the multivariate regression models of 12 studies, including these models in addition to univariate associations, and of eight studies solely presenting multivariate regression models were also analyzed in this systematic review (Table 5). These results highlight the evidence of bivariate associations between the environment and CIM. Nevertheless, socio-demographic characteristics such as age and sex/gender remained significant in nearly all regression models and tended to be important predictors of CIM. Additionally, having siblings was significantly associated with CIM in four models. 
Concerning the social environment, perceived neighborhood attributes, such as neighborhood safety and fear of strangers, remained significant correlates of CIM. Moreover, parental rules and attitudes towards independent mobility showed associations with CIM. Three physical environmental attributes were consistently associated with CIM: distance to school, car ownership and traffic. There is less evidence for neighborhood design (e.g., walkability) and degree of urbanization, but many models were controlled for urban setting and, thus, did not report this association.

\section{Sex/gender differences in CIM correlates}

Due to a limited number of studies reporting results separately for boys and girls and the heterogeneity of correlates, no evidence can be found for sex/gender-specific correlates of independent mobility. Mobility licenses were positively associated with CIM for boys and girls. Two further correlates analyzed in two different studies $[36,52]$ were school-specific walkability and parental perception of traffic, which yielded inconsistent results for girls and boys (Table 3). Concerning the results of multivariate regression models, only for physical environmental attributes differences were reviewed between boys and girls. For girls only, neighborhood design, such as walkability and land use mix as well as access to a bike, was associated with girls' independent mobility [48, 52]. Car ownership and destination accessibility (e.g., parks, shopping centers, and recreation venues) were significant correlates of independent mobility in boys but not in girls [48, 52]. Inconsistent associations were reported for traffic with studies reporting associations for boys and girls and only for girls [33, 35, 48].

\section{Discussion}

The aim of this systematic review was to identify social and physical environmental correlates of independent mobility in children with a special focus on sex/gender. Associations of CIM destination and license and social environment were consistently positive, except for fear of strangers and crime. Car ownership and urban setting showed consistently negative associations with CIM License and CIM destination, respectively. However, five physical environmental attributes (dog ownership, shorter distance to school, school density, remote places, and new urban structure) were positively associated with CIM destination. Differences in correlates of independent mobility in boys and girls were found solely for the physical environment, with neighborhood design and bike ownership influencing girls' independent mobility and associations of destination accessibility and car ownership with boys' independent mobility.
CIM is related to physical activity, e.g., if children are walking or cycling without adult accompaniment. However, correlates of CIM seem to be slightly different to correlates of physical activity [43]. CIM tends to be more determined by the social environment than the physical environment. In comparison, physical activity is more associated with objectively measured environmental attributes such as walkability and traffic speed/volume [43]. For CIM other factors may be important to address when developing intervention programs, such as social norms, parents' perceptions of neighborhood, and parental rules. Particularly, CIM license depends on parents' perception of neighborhood environment [24, 49, 61]. As many studies have demonstrated that CIM increases with children's age [23, 25, 62], parental restrictions on CIM probably decrease with children's age while physical environmental attributes which support independent active travel may gain in importance.

Previous reviews of the physical environment and children's travel behavior reported inconsistent results and non-occurring associations for several physical attributes as well $[39,65]$. For children, the impact of the physical environment is potentially influenced by granting (or not) of mobility licenses by their parents who are literally the gatekeepers of their travel behavior. For adults a variety of neighborhood physical features, such as walkability, street connectivity and access to services, are consistently associated with active travel behavior $[66,67]$.

The two constructs "parental perception of traffic" and "traffic (objective)" supported the conclusion that social environmental attributes determine CIM more than those of the physical environment: traffic perception was consistently associated with CIM; inconsistent associations were reported for objectively measured traffic. Nevertheless, physical environmental correlates with inconsistent results (e.g., school-specific walkability, access to parks, street connectivity, and land use mix) need to be addressed in future research as some studies have shown that activity-friendly environments can promote active travel behavior [68].

Results of multivariate regression models of studies included in this review underline the differing relevance of the social and physical environment for CIM. Age, sex/gender and parental perceived neighborhood environment tend to be represented as significant correlates of CIM [12, 25, 26, 32, 49, 50, 61, 62]. On the other hand, few physical environmental correlates (e.g., car ownership, and distance) remained significant in multivariate regression models $[26,32,50,52,56,57$, 62]. Although these models help to identify the actual effects of different correlates on CIM, the comparison 
Table 5 Results of multivariate regression models showing only significant correlates of CIM ( $n=20$ studies)

\begin{tabular}{|c|c|c|c|}
\hline Study source & $\begin{array}{l}\text { Socio-demographic } \\
\text { and psychosocial characteristics }\end{array}$ & Social environment & Physical environment \\
\hline Alparone et al. [25] & Age, birth order & $\begin{array}{l}\text { fear of strangers } \\
\text { Perception of positive potentiality of } \\
\text { outdoor autonomy }\end{array}$ & n. s. \\
\hline Buliung et al. [32] (to school) & $\begin{array}{l}\text { Age,sex/gender } \\
\text { Flexible work schedule }\end{array}$ & Neighborhood safety & $\begin{array}{l}\text { Distance } \\
\text { Traffic }\end{array}$ \\
\hline Buliung et al. [32] (from school) & $\begin{array}{l}\text { Age, sex/gender, } \\
\text { Flexible work schedule, fathers' } \\
\text { employment status }\end{array}$ & Neighborhood safety & Traffic \\
\hline Christian et al. [49] & Age, older siblings & $\begin{array}{l}\text { Neighborhood safety } \\
\text { Social norms }\end{array}$ & n. s. \\
\hline Cordovil et al. [23] & Age & Mobility license & $\begin{array}{l}\text { Car ownership } \\
\text { Distance }\end{array}$ \\
\hline Fyhri et al. [62] & Age, sex/gender & $\begin{array}{l}\text { Neighborhood safety } \\
\text { Fear of strangers }\end{array}$ & $\begin{array}{l}\text { Parents car use frequency } \\
\text { Distance }\end{array}$ \\
\hline Janssen et al. [63] & Age & $\begin{array}{l}\text { Neighborhood safety } \\
\text { Fear of crime }\end{array}$ & n. s. \\
\hline Johannson [56] CIM license & Age, maturity, siblings & $\begin{array}{l}\text { Neighborhood safety } \\
\text { Traffic perception } \\
\text { Need to protect }\end{array}$ & n. s. \\
\hline Johannson [56] CIM range & Age, maturity, siblings & Attitude towards CIM & $\begin{array}{l}\text { Car ownership } \\
\text { Traffic }\end{array}$ \\
\hline Kytta [16] (Finnish data) & n. s. & Mobility license & Urbanization \\
\hline Kytta [64] (Belrushian data) & Sex/gender & n. s. & Urbanization \\
\hline Lam and Loo [50] & $\begin{array}{l}\text { Age } \\
\text { Household income, family structure, } \\
\text { mothers'employment status, } \\
\text { domestic helpers at home }\end{array}$ & n. s. & $\begin{array}{l}\text { Distance } \\
\text { Urbanization } \\
\text { School density }\end{array}$ \\
\hline Lin et al. [57] & Siblings & n.s. & $\begin{array}{l}\text { Car ownership } \\
\text { Distance }\end{array}$ \\
\hline Mammen et al. [26] & $\begin{array}{l}\text { Age } \\
\text { Language spoken at home }\end{array}$ & $\begin{array}{l}\text { Fear of strangers } \\
\text { Traffic perception }\end{array}$ & $\begin{array}{l}\text { Car ownership } \\
\text { Distance }\end{array}$ \\
\hline Prezza et al. [12] & Age, sex/gender & Neighborhood Friendliness & $\begin{array}{l}\text { Park accessibility } \\
\text { Urban structure } \\
\text { Courtyard }\end{array}$ \\
\hline Santos et al. [59] & n. r. & $\begin{array}{l}\text { Neighborhood safety } \\
\text { Parents' physical activity }\end{array}$ & \\
\hline Veitch et al. [60] school & Child enjoys walking & child's personal safety & Walking facilities \\
\hline Veitch et al. [60] ${ }^{\mathrm{b}}$ local destinations & n. s. & $\begin{array}{l}\text { Many other children with in the } \\
\text { neighborhood }\end{array}$ & n.s. \\
\hline Wolfe and McDonald [61] & Age, race & Neighborhood safety & Housing unit density \\
\hline \multicolumn{4}{|c|}{ Multivariate regressions models with separate results for boys and girls } \\
\hline Carver et al. $[52]^{d}$ girls & n. r. & Parent encouragement for walking & $\begin{array}{l}\text { Street connectivity } \\
\text { Land use mix }\end{array}$ \\
\hline Carver et al. [52] boys & n. r. & Parental rules towards outdoor play & Car ownership \\
\hline Foster et al. [36] girls & n. r. & $\begin{array}{l}\text { Fear of strangers } \\
\text { Informal social control }\end{array}$ & n. r. \\
\hline Foster et al. [36] boys & n. r. & Fear of strangers & n. r. \\
\hline Ghekiere et al. [35] girls & $\begin{array}{l}\text { Grade } \\
\text { Cycle skills } \\
\text { Traffic skills }\end{array}$ & n. s. & traffic \\
\hline Ghekiere et al. [35] boys & $\begin{array}{l}\text { Grade } \\
\text { Cycle skills } \\
\text { Traffic skills }\end{array}$ & n.s. & n.s. \\
\hline Villanueva et al. [35] ${ }^{\mathrm{e}}$ girls & Child's confidence & $\begin{array}{l}\text { Neighborhood safety } \\
\text { Traffic perception } \\
\text { Confidence in child's ability }\end{array}$ & $\begin{array}{l}\text { Bike ownership } \\
\text { School-specific walkability }\end{array}$ \\
\hline
\end{tabular}


Table 5 (continued)

\begin{tabular}{|c|c|c|c|}
\hline Study source & $\begin{array}{l}\text { Socio-demographic } \\
\text { and psychosocial characteristics }\end{array}$ & Social environment & Physical environment \\
\hline Villanueva et al. [48] boys & Child's confidence & $\begin{array}{l}\text { Neighborhood friendliness } \\
\text { Traffic perception } \\
\text { confidence in child's ability }\end{array}$ & $\begin{array}{l}\text { Distance to green space } \\
\text { Count of shopping centers, recreation } \\
\text { venues, community services and } \\
\text { retail shops } \\
\text { Park attractiveness }\end{array}$ \\
\hline Villlanueva et al. [48] ${ }^{\mathrm{e}}$ girls & Child's confidence & $\begin{array}{l}\text { Neighborhood safety } \\
\text { People on walks in the neighbor- } \\
\text { hood } \\
\text { Confidence in child's ability }\end{array}$ & $\begin{array}{l}\text { Bike ownership } \\
\text { School-specific walkability }\end{array}$ \\
\hline Villlanueva et al. [48] boys & Child's confidence & $\begin{array}{l}\text { Neighborhood safety } \\
\text { Many other children with in the } \\
\text { neighborhood } \\
\text { Traffic perception } \\
\text { confidence in child's ability }\end{array}$ & \\
\hline
\end{tabular}

Abbreviations: CIM children's independent mobility, n. r. not reported, n. s. not significant

a Adjusted for child's age and gender

b Controlled for sex and age of child, urban/rural location, maternal education and employment, distance to school, whether the child changed school between T1

and $\mathrm{T} 2$, and clustering within suburbs

c Controlled for sex and age of child, urban/rural location, maternal education and employment, and clustering within suburbs

d Controlled for parental education level, distance from home to school, urban/rural

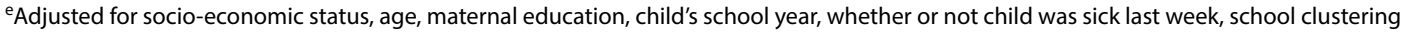

of findings should be interpreted carefully as all regression models integrated a wide range of socio-demographic, social and physical environmental correlates and adjusted for different variables.

Only three studies focused on parental physical activity and parents' and friends' encouragement for walking, but the results were inconsistent $[52,59,63]$. However, family and peer support and modeling seemed to be relevant for CIM as in other studies having siblings and friends was positively related to CIM [33, 49, 56, 57]. Previous reviews showed that parental physical activity and physical activity of peers is associated with youth activity behaviors $[47,69,70]$. Additionally, a study by Mackett et al. [71] demonstrated that girls in particular were only allowed to go out if they were accompanied by other children. In order to promote CIM, future research should specially focus on parent and peer related correlates of CIM, such as social support and social modelling. Furthermore, parent perceived environmental factors, such as fear of crime and neighborhood safety which were inconsistently associated with CIM, demand further research.

In physical activity, sport participation and CIM sex/ gender differences are consistently reported, with girls tending to be less active or rather mobile than boys [3, 12, 72]. To overcome these sex/gender gaps, intervention programs need to be sex/gender-sensitive and take sex/gender-specific situations into account. A study by Reimers et al. [72] pointed out that girls residing longer destinations from the nearest sport facilities are less likely to take part in club sport activities. This relationship has not been observed in boys in this study. Promoting independent mobility in girls could therefore increase both their physical activity on the way to sports facilities and other physical activities by enabling girls to get access to other physical activity facilities or locations. CIM could be a door opener to get access to physical activity facilities and locations, such as gyms, playgrounds, parks etc., where children can participate in various physical activities and are able to meet other children to actively play with. This could be true for girls and boys. Promoting CIM in girls and boys could contribute to physical activity as active living behavior. Since an active living behavior is often established in childhood and adolescence, it could also affect physical activity and health in adulthood $[73,74]$.

Thus, this systematic review was the first to investigate sex/gender-related correlates of CIM for the development of effective intervention programs. Sex/gender differences with regard to the extent of independent mobility are consistently reported as being lower for girls than for boys [12, 34, 58]. To promote CIM, especially in girls, it is necessary to sufficiently understand the impact of social and environmental influences on girls' and boys' independent travel behaviors. However, only seven studies were identified that reported results separately for boys and girls [33, 35, 36, 48, 52-54]. Due to heterogeneity in the correlates and differing statistical methods, the results of the studies did not provide evidence of sex/ gender-related correlates of CIM. This marks a research 
gap which must be addressed in future studies to develop effective sex/gender-specific intervention programs for boys and girls.

In this systematic review all studies with a quantitative design were included, irrespective of whether they were cross-sectional analyses or longitudinal analyses. Thus, the objective was to identify correlates of CIM because the number of high quality longitudinal studies was very limited. However to identify causal relationships between the environment and CIM, more longitudinal studies are needed.

According to Sharmin and Kamruzzaman [40], in the present systematic review, CIM was categorized into four different types: CIM destination, CIM license, CIM time, and CIM range. However, the majority of studies examined CIM destination and CIM license, and the results were solely presented for these two definitions of CIM. A study by Bhosale et al. [75] showed that CIM license and destination access are significantly correlated, which explains the similarities in the social and physical environmental correlates of both CIM types.

Apart from similarities between CIM license and CIM destination, some studies $[49,61]$ reported that the correlates of independent mobility differ between visited destinations. For example distance to park [49] and social control [61] were correlated with specific destinations (i.e., a park and a friend's house, respectively) but not with overall independent mobility. Due to a lack of comparability, in this systematic review, the results were only analyzed for overall independent mobility. More research is required to separate correlates by visited destination.

CIM range was analyzed in merely three studies and CIM time not at all. Time and range may be insufficient indicators for CIM or simply rarely used at this stage. Using GPS as an objective measure of CIM could provide a more comprehensive understanding of CIM time and CIM range as indicator of CIM [76].

Based on the results of the methodological quality assessment, the lack of a standardized definition and measurement of independent mobility and environmental correlates limited the comparison of the included studies. In fact, a wide variety of measurements were used to determine CIM. Although results were separated for CIM license and CIM destination, measurements differed for child and parental report, with no study employing objective measures. To compare studies Bates and Stone [76] recommended using a standardized methodological design and a combination of subjective and objective measurements of CIM in future research.

Additionally, a wide selection of social and physical environmental correlates was used in the studies to evaluate the relationship between the environment and CIM.
Thus, some correlates appeared only in one study, which provided only limited evidence. Furthermore, terminological differences were observed between researchers. For example, "stranger danger" was paraphrased as "trust in strangers" [24], "worried about strangers" [32, 33], and "fear of strangers" [32], which based on the description and measurement evaluated the same construct or the contrary. Due to such differences the comparison of various studies might be limited. Thus, future research should aim to create and apply standardized terms. Moreover, the heterogeneity of applied measurements for the same social and physical construct in different studies and the lack of reliable tools could lead to inconsistent findings as well.

The lack of generalizability of study results is caused by insufficient response rates in almost all studies. Acceptable response rates should to be at least $80 \%$ [46]. The response rate of included studies ranged between $18 \%$ [53] and 100\% [64] with merely two studies above the recommended $80 \%[25,64]$.

To analyze the influence of the methodological quality of studies on strength of evidence and the associations evaluated, differences in the results between high and low quality studies were considered. However, no systematic differences were found for positive, negative and non-existing associations in high and low quality studies. Thus, the methodological quality has no potential influence on inconsistent associations.

\section{Strengths and limitations}

A strength of this review is the systematic search of relevant primary studies employing several search engines and a comprehensive list of search terms. Furthermore, the reference lists of all studies included were reviewed for additional sources. Another strength is that two independent reviewers (IM, CS) systematically screened relevant articles in three steps. Additionally, to evaluate the risk of bias a quality assessment was developed based on existing criteria lists for cross-sectional studies focusing on the methodological quality of the studies included. All results (bivariate and multivariate associations) were included in this systematic review, but analyzed separately as the multivariate associations integrated different correlates and, thus, were not directly comparable with the bivariate associations. Nevertheless, including both statistical methods helps to provide a further understanding of the relationship between socio-demographic characteristics, the social environment, and the physical environment with CIM. Stratifications of results by CIM definition provided additional information on the relationship between the environment and CIM.

A first limitation of this systematic review is the lack of evidence for causal relationships between the 
environment and CIM, because only two studies contained a longitudinal study design. Secondly, associations were only considered by significance and direction, not by effect size. Thirdly, conclusions may be heavily influenced by the low methodological quality of the studies and by individual findings of single studies, because many conclusions were based only on the result of one study. Additionally, no association demonstrated strong evidence, i.e., associations with at least four studies of high quality reporting the significant association in the expected direction. The fourth limitation is that only English- and German-language articles were considered for this review. Finally, as few studies reported sex/gender-specific results, sex/gender-related correlates could not be analyzed in detail.

\section{Conclusion}

This systematic review provides an overview of social and environmental correlates of independent mobility in children and highlights important research gaps.

Based on the socio-ecological perspective, this systematic review pointed out important social and physical environmental correlates which could be considered when developing intervention programs to halt the decline of CIM, especially in girls. Overall, the synthesis of existing studies revealed that neighborhood safety, fear of crime and strangers, parental support and perception of traffic are significant social correlates. Furthermore, car ownership, distance, and neighborhood design belong to physical environmental attributes, which influence CIM. To possibly address factors, such as neighborhood safety or fear of crime, which are limitedly modifiable and more determined by political decisions concerning the domestic security, intervention programs should focus on the interaction between social and physical environment [77]. Promoting children to walk or cycle to school together with other children instead of walking alone and promoting their competence to travel safely could be one way to deter parent's concerns about safety in the neighborhood and to expand mobility licenses [78].

Additionally, this systematic review identified future directions of research and suggests that the influence of the environment on CIM has not yet been fully understood. One important aspect is the implementation of longitudinal studies focusing on children's independent mobility to get insights into causal relationships of the social and physical environment and CIM. Additionally, to foster a robust understanding of the impact of the social and physical environment on CIM, more studies employing comparable measuring standards for CIM and environmental predictors are needed.

Furthermore, this systematic review showed that sex/ gender-related correlates are limitedly evaluated in literature until now. Promoting independent mobility, especially in girls, could additionally promote their physical activity and thus, contributes to healthy development in children [11]. To consider social inequalities in sport participation between boys and girls and the sex/gender gap in CIM future research should evaluate sex/genderspecific correlates of CIM.

\section{Additional files}

Additional file 1. Characteristics of studies included on association of CIM and the social and physical environment The table shows the extracted data separated for all studies included, consisting of author(s); year of publication; country; study design; sample description (number of participants, age, sex/gender); definition, measurement, and instrument of CIM; type, measurement, and instruments of examined correlates; and main study results on the relationship between social and physical environmental factors and CIM.

Additional file 2. Quality Assessment for all studies included. The table shows the methodological quality rating of each criteria and the total quality score for all included studies.

Abbreviation

CIM: children's independent mobility.

Authors' contributions

IM drafted the manuscript, conducted the review, and synthesized the findings. AKR supervised the project. YD and AKR contributed to the concept of the paper and provided edits to the paper. All authors read and approved the final manuscript.

\section{Author details \\ 1 Faculty of Behavioral and Social Sciences, Chemnitz University of Technology, Chemnitz, Germany. ${ }^{2}$ Department of Sport and Health Sciences, Technical University of Munich, Munich, Germany.}

\section{Acknowledgements}

The authors thank Christine Schmidt (CS) and Karolina Boxberger (KB) for their assistance in the screening of the literature and the rating of methodological quality.

Competing interests

The authors declare that they have no competing interests.

Availability of data and materials

All data generated or analyzed during the current study are included in the published article and its supplementary information files.

Consent for publication

Not applicable.

Ethics approval and consent to participate

Not applicable.

\section{Funding}

The publication costs of this article were funded by the German Research Foundation/DFG and the Technische Universität Chemnitz in the funding programme Open Access Publishing.

\section{Publisher's Note}

Springer Nature remains neutral with regard to jurisdictional claims in published maps and institutional affiliations. 
Received: 9 May 2018 Accepted: 24 June 2018

Published online: 03 July 2018

\section{References}

1. Warburton DER, Nicol CW, Bredin SSD. Health benefits of physical activity: the evidence. Can Med Assoc J. 2006. https://doi.org/10.1503/cmaj.05135

2. Janssen I, LeBlanc AG. Systematic review of the health benefits of physical activity and fitness in school-aged children and youth. Int J Behav Nutr Phys Act. 2010. https://doi.org/10.1186/1479-5868-7-40.

3. Hallal PC, Andersen LB, Bull FC, Guthold R, Haskell W, Ekelund U. Global physical activity levels: surveillance progress, pitfalls, and prospects. Lancet. 2012. https://doi.org/10.1016/S0140-6736(12)60646-1.

4. WHO. Prevalence of insufficient physical activity. Geneva: WHO; 2010 http://www.who.int/gho/ncd/risk_factors/physical_activity_text/en/. Accessed 05 Apr 2018

5. Larouche R, Saunders TJ, Faulkner GEJ, Colley R, Tremblay M. Associations between active school transport and physical activity, body composition, and cardiovascular fitness: a systematic review of 68 studies. J Phys Act Health. 2014. https://doi.org/10.1123/jpah.2011-0345.

6. Gordon-Larsen P, Nelson MC, Beam K. Associations among active transportation, physical activity, and weight status in young adults. Obes Res. 2005. https://doi.org/10.1038/oby.2005.100.

7. Tranter P, Whitelegg J. Children's travel behaviours in Canberra: cardependent lifestyles in a low-density city. J Transp Health. 1994. https:// doi.org/10.1016/0966-6923(94)90050-7.

8. Page AS, Cooper AR, Griew P, Davis L, Hillsdon M. Independent mobility in relation to weekday and weekend physical activity in children aged 10-11 years: the PEACH Project. Int J Behav Nutr Phys Act. 2009. https:// doi.org/10.1186/1479-5868-6-2.

9. Mackett RL, Lucas L, Paskins J, Turbin J. The therapeutic value of children's everyday travel. Transp Res Part A Policy Pract. 2004. https://doi. org/10.1016/j.tra.2004.09.003.

10. Davis $A$, Jones $L J$. Children in the urban environment: an issue for the new public health agenda. Health Place. 1996. https://doi. org/10.1016/1353-8292(96)00003-2

11. Schoeppe S, Duncan MJ, Badland H, Oliver M, Curtis C. Associations of children's independent mobility and active travel with physical activity, sedentary behaviour and weight status: a systematic review. J Sci Med Sport. 2013. https://doi.org/10.1016/j.jsams.2012.11.001.

12. Prezza M, Pilloni S, Morabito C, Sersante C, Alparone FR, Giuliani MV. The influence of psychosocial and environmental factors on children's independent mobility and relationship to peer frequentation. J Community Appl Soc. 2001. https://doi.org/10.1002/casp.643.

13. Rissotto A, Tonucci F. Freedom of movement and environmental knowledge in elementary school children. J Environ Psychol. 2002. https://doi. org/10.1006/jevp.2002.0243.

14. Pacilli MG, Giovannelli I, Prezza M, Augimeri ML. Children and the public realm: antecedents and consequences of independent mobility in a group of 11-13-year-old Italian children. Child Geogr. 2013. https://doi. org/10.1080/14733285.2013.812277.

15. Schoeppe S, Tranter P, Duncan MJ, Curtis C, Carver A, Malone K. Australian children's independent mobility levels: secondary analyses of crosssectional data between 1991 and 2012. Child Geogr. 2016. https://doi. org/10.1080/14733285.2015.1082083.

16. Kytta M, Hirvonen J, Rudner J, Pirjola I, Laatikainen T. The last freerange children? Children's independent mobility in finland in the 1990s and 2010s. J Transp Health. 2015. https://doi.org/10.1016/j.jtran geo.2015.07.004.

17. Fyhri A, Hjorthol R, Mackett RL, Fotel TN, Kytta M. Children's active travel and independent mobility in four countries: development, social contributing trends and measures. Transp Policy. 2011. https://doi.org/10.1016/j. tranpol.2011.01.005

18. Shaw B, Bicket M, Elliott B, Fagan-Watson B, Mocca E, Hillmann M. Children's independent mobility. An international comparison and recommondation for action. London: Policy Studies Institute; 2015.

19. Sallis JF, Cervero RB, Ascher W, Henderson KA, Kraft MK, Kerr J. An ecological approach to creating active living communities. Annu Rev Public
Health. 2006. https://doi.org/10.1146/annurev.publhealth.27.02140 5.102100 .

20. Giles-Corti B, Kelty SF, Zubrick SR, Villanueva KP. Encouraging walking for transport and physical activity in children and adolescents how important is the built environment? Sports Med. 2009. https://doi. org/10.2165/11319620-000000000-00000.

21. Schmidt W. Kindheit und sportzugang im wandel: Konsequenzen fuer die bewegungserziehung? [childhood and sport in transition: consequences for physical education?]. 1993; 42(1):24-32.

22. Hillman M, Adams J, Whitelegg J. One false move. London: Policy Studies Institute; 1990.

23. Cordovil R, Lopes F, Neto C. Children's (in)dependent mobility in Portugal. J Sci Med Sport. 2015. https://doi.org/10.1016/j.jsams.2014.04.013.

24. Mitra R, Faulkner GEJ, Buliung RN, Stone MR. Do parental perceptions of the neighbourhood environment influence children's independent mobility? Evidence from Toronto, Canada. Urban Stud. 2014. https://doi. org/10.1177/0042098013519140.

25. Alparone FR, Pacilli MG. On children's independent mobility: the interplay of demographic, environmental, and psychosocial factors. Child Geogr. 2012. https://doi.org/10.1080/14733285.2011.638173.

26. Mammen G, Faulkner G, Buliung R, Lay J. Understanding the drive to escort: a cross-sectional analysis examining parental attitudes towards children's school travel and independent mobility. BMC Public Health. 2012. https://doi.org/10.1186/1471-2458-12-862

27. Christian H, Villanueva K, Klinker CD, Knuiman MW, Divitini M, Giles-Corti $B$. The effect of siblings and family dog ownership on children's independent mobility to neighbourhood destinations. Aust Nz J Publ Health. 2016. https://doi.org/10.1111/1753-6405.12528.

28. Ristvedt SL. The evolution of gender. JAMA Psychiatry. 2014. https://doi. org/10.1001/jamapsychiatry.2013.3199.

29. Kilvington J, Wood A. Gender, sex and children's play. London: Bloomsbury Publishing; 2016

30. Slater A, Tiggemann M. Gender differences in adolescent sport participation, teasing, self-objectification and body image concerns. J Adolesc 2011. https://doi.org/10.1016/j.adolescence.2010.06.007.

31. Vilhjalmsson R, Kristjansdottir G. Gender differences in physical activity in older children and adolescents: the central role of organized sport. Soc Sci Med. 2003. https://doi.org/10.1016/S0277-9536(02)00042-4.

32. Buliung RN, Larsen K, Faulkner G, Ross T. Children's independent mobility in the city of Toronto, Canada. Travel Behav Soc. 2017. https://doi. org/10.1016/j.tbs.2017.06.001

33. Villanueva K, Giles-Corti B, Bulsara M, Trapp G, Timperio A, McCormack G, et al. Does the walkability of neighbourhoods affect children's independent mobility, independent of parental, socio-cultural and individual factors? Child Geogr. 2014. https://doi.org/10.1080/14733285.2013.81231 1.

34. Brown B, Mackett R, Gong Y, Kitazawa K, Paskins J. Gender differences in children's pathways to independent mobility. Child Geogr. 2008. https:// doi.org/10.1080/14733280802338080.

35. Ghekiere A, Deforche B, Carver A, Mertens L, de Geus B, Clarys P, et al. Insights into children's independent mobility for transportation cycling which socio-ecological factors matter? J Sci Med Sport. 2017. https:// doi.org/10.1016/j.jsams.2016.08.002.

36. Foster S, Villanueva K, Wood L, Christian H, Giles-Corti B. The impact of parents' fear of strangers and perceptions of informal social control on children's independent mobility. Health Place. 2014. https://doi. org/10.1016/j.healthplace.2013.11.006.

37. Golden SD, Earp JAL. Social ecological approaches to individuals and their contexts: twenty years of health education and behavior health promotion interventions. Health Educ Behav. 2012;39(3):364-72.

38. Kok G, Gottlieb NH, Commers M, Smerecnik C. The ecological approach in health promotion programs: a decade later. Am J Health Promot. 2008;22(6):437-41.

39. Panter JR, Jones AP, van Sluijs EM. Environmental determinants of active travel in youth: a review and framework for future research. Int J Behav Nutr Phys Act. 2008. https://doi.org/10.1186/1479-5868-5-34.

40. Sharmin S, Kamruzzaman M. Association between the built environment and children's independent mobility: a meta-analytic review. J Transp Health. 2017. https://doi.org/10.1016/j.jtrangeo.2017.04.004. 
41. Qiu L, Zhu X. Impacts of housing and community environments on children's independent mobility: a systematic literature review. Int J Cont Archit. 2017. https://doi.org/10.14621/tna.20170205.

42. Moher D, Liberati A, Tetzlaff J, Altmann DG. The PRISMA Group. Preferred reporting items for systematic reviews and meta-analyses: the PRISMA Statement. PLoS Med. 2009. https://doi.org/10.1371/journ al.pmed.1000097.

43. Ding D, Sallis JF, Kerr J, Lee S, Rosenberg DE. Neighborhood environment and physical activity among youth: a review. Am J Prev Med. 2011. https://doi.org/10.1016/j.amepre.2011.06.036.

44. Analytics Clarivate. Endnote X7. Philidelphia: Clarivate Analytics; 2013

45. Downes MJ, Brennan ML, Williams HC, Dean RS. Development of a critical appraisal tool to assess the quality of cross-sectional studies (AXIS). BMJ Open. 2016. https://doi.org/10.1136/bmjopen-2016-011458.

46. Uijtdewilligen L, Nauta J, Singh AS, van Mechelen W, Twisk JWR, van der Horst $\mathrm{K}$, et al. Determinants of physical activity and sedentary behaviour in young people: a review and quality synthesis of prospective studies. Br J Sport Med. 2011. https://doi.org/10.1136/bjsports-2011090197

47. Sallis JF, Prochaska JJ, Taylor WC. A review of correlates of physical activity of children and adolescents. Med Sci Sports Exerc. 2000. https ://doi.org/10.1097/00005768-200005000-00014

48. Villanueva K, Giles-Corti B, Bulsara M, Timperio A, McCormack G, Beesley $B$, et al. Where do children travel to and what local opportunities are available? The relationship between neighborhood destinations and children's independent mobility. Environ Behav. 2012. https://doi. org/10.1177/0013916512440705.

49. Christian $\mathrm{H}$, Klinker CD, Villanueva K, Knuiman MW, Foster SA, Zubrick SR, et al. The effect of the social and physical environment on children's independent mobility to neighborhood destinations. J Phys Act Health. 2015. https://doi.org/10.1123/jpah.2014-0271.

50. Lam WWY, Loo BPY. Determinants of children's independent mobility in Hong Kong. Asian Trans Stud. 2014. https://doi.org/10.11175/easts ats.3.250

51. Broberg A, Salminen S, Kytta M. Physical environmental characteristics promoting independent and active transport to children's meaningful places. Appl Georgr. 2013. https://doi.org/10.1016/j.apgeo g.2012.11.014.

52. Carver A, Panter JR, Jones AP, van Sluijs EMF. Independent mobility on the journey to school: a joint cross-sectional and prospective exploration of social and physical environmental influences. J Transp Health. 2014:1(1):25-32.

53. Carver A, Timperio AF, Crawford DA. Young and free? A study of independent mobility among urban and rural dwelling Australian children. J Sci Med Sport. 2012. https://doi.org/10.1016/j.jsams.2012.03.005.

54. Carver A, Watson B, Shaw B, Hillman M. A comparison study of children's independent mobility in England and Australia. Child Geogr. 2013. https://doi.org/10.1080/14733285.2013.812303.

55. Chaudhury M, Oliver M, Badland H, Garrett N, Witten K. Using the public open space attributable index tool to assess children's public open space use and access by independent mobility. Child Geogr. 2017. https://doi.org/10.1080/14733285.2016.1214684.

56. Johansson M. Environment and parental factors as determinants of mode for children's leisure travel. J Environ Psychol. 2006. https://doi. org/10.1016/j.jenvp.2006.05.005

57. Lin E-Y, Witten K, Oliver M, Carroll P, Asiasiga L, Badland H, et al. Social and built-environment factors related to children's independent mobility: the importance of neighbourhood cohesion and connectedness. Health Place. 2017. https://doi.org/10.1016/j.healthplace.2017.05.002

58. Lopes F, Cordovil R, Neto C. Children's independent mobility in Portugal: effects of urbanization degree and motorized modes of travel. J Transp Health. 2014. https://doi.org/10.1016/j.jtrangeo.2014.10.002.

59. Santos MP, Pizarro AN, Mota J, Marques EA. Parental physical activity, safety perceptions and children's independent mobility. BMC Public Health. 2013. https://doi.org/10.1186/1471-2458-13-584.
60. Veitch J, Carver A, Salmon J, Abbott G, Ball K, Crawford D, et al. What predicts children's active transport and independent mobility in disadvantaged neighborhoods? Health Place. 2017. https://doi org/10.1016/j.healthplace.2017.02.003.

61. Wolfe MK, McDonald NC. Association between neighborhood social environment and children's independent mobility. J Phys Act Health. 2016. https://doi.org/10.1123/jpah.2015-0662.

62. Fyhri A, Hjorthol R. Children's independent mobility to school, friends and leisure activities. J Transp Health. 2009. https://doi.org/10.1016/j. jtrangeo.2008.10.010

63. Janssen I, Ferrao T, King N. Individual, family, and neighborhood correlates of independent mobility among 7 to 11-year-olds. Prevent Med Rep. 2015. https://doi.org/10.1016/j.pmedr.2015.12.008.

64. Kytta M. The extent of children's independent mobility and the number of actualized affordances as criteria for child-friendly environments. J Environ Psychol. 2004. https://doi.org/10.1016/s0272-4944(03)00073-2.

65. Rothman L, Buliung R, Macarthur C, To T, Howard A. Walking and child pedestrian injury: a systematic review of built environment correlates of safe walking. Inj Prev. 2014. https://doi.org/10.1136/injuryprev-2012040701.

66. Panter JR, Jones A. Attitudes and the environment as determinants of active travel in adults: What do and don't we know? J Phys Act Health. 2010. https://doi.org/10.1123/jpah.7.4.551.

67. Cerin E, Nathan A, van Cauwenberg J, Barnett DW, Barnett A, Council Environm Phys A. The neighbourhood physical environment and active travel in older adults: a systematic review and meta-analysis. Int J Behav Nutr Phys Act. 2017. https://doi.org/10.1186/s12966-017-0471-5.

68. Broberg A, Kytta M, Fagerholm N. Child-friendly urban structures: buller by revisited. J Environ Psychol. 2013. https://doi.org/10.1016/j.jenvp 2013.06.001.

69. Xu HL, Wen LM, Rissel C. Associations of parental influences with physical activity and screen time among young children: a systematic review. J Obes. 2015. https://doi.org/10.1155/2015/546925.

70. Hutchens A, Lee RE. Parenting practices and children's physical activity: an integrative review. J Sch Nurs. 2018. https://doi.org/10.1177/10598 40517714852

71. Mackett R, Brown B, Gong Y, Kitazawa K, Paskins J. Children's independent movement in the local environment. Built Environ. 2007. https:// doi.org/10.2148/benv.33.4.454

72. Reimers AK, Wagner M, Alvanides S, Steinmayr A, Reiner M, Schmidt $S$, et al. Proximity to sports facilities and sports participation for adolescents in Germany. PLoS ONE. 2014. https://doi.org/10.1371/journ al.pone.0093059.

73. Cleland V, Dwyer T, Venn A. Which domains of childhood physical activity predict physical activity in adulthood? A 20-year prospective tracking study. Br J Sports Med. 2012. https://doi.org/10.1136/bjspo rts-2011-090508.

74. Malina RM. Tracking of physical activity and physical fitness across the lifespan. Res Q Exerc Sport. 1996:67(3 Suppl):S48-57.

75. Bhosale J, Duncan S, Stewart T, Chaix B, Kestens Y, Schofield G. Measuring children's independent mobility: comparing interactive mapping with destination access and licence to roam. Child Geogr. 2017. https //doi.org/10.1080/14733285.2017.1293232

76. Bates B, Stone MR. Measures of outdoor play and independent mobility in children and youth: a methodological review. J Sci Med Sport. 2015. https://doi.org/10.1016/j.jsams.2014.07.006.

77. Bartholomew Eldredge LK, Markham CM, Ruiter RAC, Fernãndez ME, Kok G, Parcel GS. Planning health promotion programs: an intervention mapping approach. London: Wiley; 2016.

78. Bennetts SK, Cooklin AR, Crawford S, D'Esposito F, Hackworth NJ, Green J, et al. What influences parents' fear about children's independent mobility? Evidence from a state-wide survey of Australian parents. Am J Health Promot. 2017. https://doi.org/10.1177/0890117117740442. 